Journal of Accident and Emergency Medicine 1994 11, 117-120

\section{Motorcyclists, full-face helmets and neck injuries: can you take the helmet off safely, and if so, how?}

\author{
T. BRANFOOT
}

Department of Surgery, North Staffordshire Trauma Centre, Stoke-on-Trent

\section{SUMMARY}

Injured motorcyclists may have a damaged and unstable cervical spine (C-spine). This paper looks at whether a helmet can be safely removed, how and when should this be done? The literature is reviewed and the recommendations of the Trauma Working party of the Joint Colleges Ambulance Liaison Committee are presented.

Key words: cervical spine injuries, full face helmets, motorcyclists

\section{INTRODUCTION}

Motorcycle accident and injury rates are falling each year, but they remain significant - in 1985 there were over 600 deaths and 12000 serious injuries to motorcyclists. ${ }^{1}$ The most common injuries are fractures of the lower leg, ${ }^{2,3}$ the most lethal are head injuries. ${ }^{4}$.

The importance of head injuries and the protective worth of helmets was discussed as early as $1941 .^{5}$ Their value in reducing mortality and morbidity has been clearly shown. ${ }^{6}$ The wearing of helmets was made compulsory in the United Kingdom in 1973. The American experience of repeal and reinstatement of legislation compelling helmet use has under lined their growth. ${ }^{7}$

Enforcement of helmet use has been opposed by many motorcyclists, led by the UK's Motorcycle Action Group, mainly on grounds of infringement of civil liberties. They have also argued that helmets, because of their mass, increase the possibility of neck injuries. ${ }^{8}$ Helmets have also been held responsible for other injuries, e.g. rib fractures ${ }^{9}$ and basal skull fractures. ${ }^{10}$ These arguments are not valid against compulsory wearing of helmets either individually or collectively, as their overall protective effects have been demonstrated to reduce fatalities by about $30 \% .{ }^{11}$ It does, however, increase concern about cervical spine injuries in those dealing with injured motorcyclists. This is especially so when confronted by a motorcyclist wearing a full-face helmet, as removal may entail significant movement of the neck. It is important to realize that the overall incidence of cervical spine injuries is low in survivors - approximately $1 \%$ overall (Table 1), whilst this rises to $9 \%$ in post mortem studies (Table 2). Concern should also be focused on thoracic and lumbar spine injuries which are common in surviving motorcyclists (Table 3).

Table 1. Incidence of cervical spine injury

\begin{tabular}{lcc}
\hline Study & $\begin{array}{c}\text { Number of } \\
\text { patients }\end{array}$ & $\begin{array}{c}\text { C-spine injuries } \\
\text { reported (\%) }\end{array}$ \\
\hline Horner et al. $^{23}$ & 57 & $0(0)$ \\
Andrew. $^{24}$ & 145 & $0(0)$ \\
Zettas et $a l .^{25}$ & 260 & $1(0.4)$ \\
Drysdale et $a l^{4}$ & 1273 & $1(0.1)$ \\
Haddad et al. $^{26}$ & 77 & $3(3.9)$ \\
Kupferschmid et al..$^{27}$ & 266 & $4(1.5)$ \\
Carr et al. ${ }^{28}$ & 397 & $12(3)$ \\
Bachulis et al. & 367 & $20(5.4)$ \\
\hline
\end{tabular}

Table 2. Incidence of cervical spine injury revealed at post mortem

\begin{tabular}{lcc}
\hline Study & $\begin{array}{c}\text { Number of } \\
\text { post mortems }\end{array}$ & C-Spine injuries (\%) \\
\hline Larsen et al. $^{29}$ & 41 & $4(10)$ \\
Krantz $^{30}$ & 132 & $10(8)$ \\
Bjornstig et al. $^{31}$ & 129 & $12(9)$ \\
\hline
\end{tabular}

Table 3. Studies of cervical, thoracic and lumbar spine injuries in motorcyclists

\begin{tabular}{lccc}
\hline & \multicolumn{3}{c}{ Injuries } \\
\cline { 2 - 4 } \multicolumn{1}{c}{ Study } & Cervical & Thoracic & Lumbar \\
\hline Shrosbree $^{32}$ & 5 & 16 & 0 \\
Kupferschmid et al. $^{27}$ & 4 & 13 & 0 \\
Carr et al. $^{28}$ & 12 & 20 & 17 \\
\hline
\end{tabular}

Correspondence:

T. Branfoot, Department of Surgery, North Staffordshire Royal Infirmary, Hartshill Stoke-on-Trent, UK 


\section{T. Branfoot}

The conscious motorcyclist has often removed his own helmet before the emergency services are involved. If not it has been argued that the helmet should be left in place unless 'it obstructs breathing, if the casualty is vomiting, or if there are severe head injuries'. ${ }^{12}$ It has been suggested that the helmet is a useful means of applying traction to, or stabilizing, the neck, ${ }^{13}$ and that the helmet should be left in place and ignored until the primary survey, resuscitation and lateral $\mathrm{C}$-spine radiographs have been completed. ${ }^{14}$

However, it is difficult to monitor the airway safely with a full face helmet in place, and it would be impossible to rapidly clear vomit from, or intubate, such a patient. The full face helmet has also been implicated in re-breathing ${ }^{15}$ and $\mathrm{CO}_{2}$ retention. ${ }^{16}$ This is clearly unacceptable, and either the entire helmet, or the chin piece, must be removed.

Removal of the helmet by one or two people has been described. ${ }^{12,17}$ Proper evaluation of such techniques is limited and contradictory. Apraheim et al. ${ }^{14,18}$ describe a cadaver model with a surgically created C 5-6 injury. Finding helmet removal to adversely affect this injury, they advise leaving the helmet alone in the field and removing it with castcutters in the accident and emergency (A\&E) department. Meyer \& Daniel used fluroscopy and lateral C-spine radiographs to study helmet removal in conscious volunteers, ${ }^{13}$ finding minimal flexion of the spine if the shoulders are elevated.

Cutting the helmet away by bi-valving it with plaster-cast cutters is proposed by Apraheim's study. ${ }^{14.18}$ This would be slow and very difficult with modern, well-fitting, high-quality helmets. A better technique is to cut through the chin piece with a vibrating saw (one has been developed for this purpose) to convert a 'full-face' helmet into a 'faceless' helmet which can be removed easily and safely.

Apraheim's study ${ }^{14,18}$ fails to consider the considerable support given to a spine by overlying muscle in spasm which is not present in a cadaver. Meyer and Daniel's ${ }^{13}$ results from cooperative volunteers are perhaps unrepresentative of an unconscious patient, and certainly cannot allow for an uncooperative, restless or combative patient. A search of the literature has found no other relevant studies.

The movements of the C-spine in intubation/ airway management offer useful parallels however. Apraheim's ${ }^{14,18}$ cadaver model suggests 'unacceptable movement of a surgically created unstable C-spine injury with virtually any airway manouvre'; although the same problems of active stability are involved here, a cadaver making a poor model of a patient. The use of traction to correct this has been shown to be potentially detrimental, and to be avoided. ${ }^{19}$ Although recommended by the Advanced Trauma Life Support (ATLS) Manual, ${ }^{20}$ 'manual cervical immobilization during oro-tracheal intubation has little, if any, evidence to support its safety' warns Joyce. ${ }^{21}$ Practical realities, however are perhaps different. Holley \& Jorden ${ }^{22}$ reported a series of 123 patients with $140 \mathrm{C}$-spine fractures: 94

Table 4. The removal of motorcyclists helmets: Recommendations from the trauma working party of the JCALC, January 1992. A.D. Redmond (Chairman), H. Baderman, H. Baker, T. Branfoot, G. Nolan and B. Chambers

(1) All helmets always off. There are no circumstances in which concern for the neck should override the risk to the airway in an injured motorcyclist.

(2) Self-removal is best. In most instances the motorcyclist will have already removed the helmet himself. A fully conscious patient with a neck injury will have pain and tenderness in the neck. If he removes the helmet himself under supervision he can be instructed to stop at the onset of pain or pins and needles in the limbs.

(3) Keep the patient lying flat. The greatest risk of further neurological damage from an unstable fracture/dislocation occurs when injured patients are allowed to stand or sit up.

(4) $A B C$ 's take priority. More avoidable injuries (including those to the spine) occur as the result of inadequate resuscitation rather than inappropriate movement. The primary survey of the ATLS course always comes first.

(5) Get help. Removal is easier and safer with two people.

(6) Two people use their two hands. With the patient lying flat one rescuer steadies the neck with their hands placed in front of and behind the neck to prevent flexion and extension. The other places their hands on either side of the helmet and draws it carefully from the head, avoiding rotation of the neck.

(7) Use a helmet saw if available. The immediate removal of the chin piece from the helmet with a portable saw will clearly give rapid access to the airway without movement of the neck and facilitate safer removal of the whole helmet. The saw need not be used on the helmet itself. It is more dense and removal will be prolonged. The noise of the saw within the helmet is considerable and therefore distressing. This will be minimized if cutting is restricted to the chin piece but responsive patients must be forwarned. Small portable saws, designed for this purpose should be adopted as standard equipment for all emergency ambulances. 
Motorcyclists, helmets and neck injuries patients were intubated, 29 orally, all with in-line stabilization without any neurological complications. They concluded that 'under controlled circumstances, patients with unstable C-spine fractures can be safely intubated with standard non-surgical procedures'. If this is so, then stabilization is probably reasonably safe when removing a helmet.

\section{CONCLUSIONS}

The risks to safe management of the airway are considerable in a patient wearing a full-face helmet. Cervical spine injuries are reasonably rare in motorcyclists. It is important to remove the helmet quickly and safely. Supervised self-removal by the conscious patient is probably best. In the unconscious patient removal with stabilization of the C-spine (preferably by two people) is safest. Evidence is conflicting, but practical experience suggests that the low chance of inflicting or exacerbating a cervical cord injury in an unstable neck is far out-weighed by the risks to the airway in an injured motorcyclist who's full-face helmet is left on.

These conclusions were presented to the Joint Royal Colleges Ambulance Liaison Committee (JCALC) and their recommendations are shown in Table 4.

\section{REFERENCES}

1. Bull J. (1988) Motorcycling, a high-risk activity. Injury 19(3), 3.

2. Craig G.R., Sleet R. \& Wood S.K. (1984) Lower limbs injuries in motorcycle accidents. Injury 15(3), 163-166.

3. Findley J.A. (1972) The motorcycle tibia. Injury 4(1), 75-78.

4. Drysdale W.F., Kraus J.F., Franti C.E. \& Riggins R.S. (1975) Injury patterns in motorcycle collisions. Journal of Trauma 15(2), 99-115.

5. Cairns H. (1941) Head injuries in motorcyclists, the importance of the crash helmet. British Medical Journal 2, 465-471.

6. Bachulis B.L., Sangster W., Gonell G.W. \& Long W.B. (1988) Patterns of injury in helmeted and nonhelmeted motorcyclists. American Journal of Surgery 155(5), 708-711.

7. Chernier T.C. \& Evans L. (1987) Motorcycle fatalities and the repeal of mandatory helmet wearing laws. Accident Annals and Prevention 19(2), 133-139.

8. Huston R.R. \& Sears J. (1981) Effect of protective helmet mass on head/neck dynamics. Journal of Biomechanical Engineering 103, 19-23.

9. Hoekestra J.H. \& Kingma L.M. (1985) Bilateral first rib fractures induced by integral crash helmets. Journal of Trauma 25(6), 566-567.

10. Cooter R.D., David J.D., McLean A.J. \& Simpson D.A. (1988) Helmet-induced skull base fracture in a motorcyclist. Lancet 84-85.

11. Watson G.S., Zador P.L. \& Wilks A. (1981) Helmet use, helmet use laws and motorcyclist fatalities. American Journal of Public Health 71(3), 297-300.

12. First Aid Manual

13. Meyer \& Daniel (1985)

14. Apraheim C., Thompson B.M. \& Darin J.C. (1984) Recommended helmet removal techniques in a cervical spine-injured patient. Journal of Trauma 24(a), 841-842.

15. Greenbaum R., Malins A.F., Davies R. \& Baskett P.J.F. (1982) British Medical Journal 284, 774-775.

16. Malins A.F., Curnow J.S., Baskett P.J.F. \& Greenbaum R. (1984) Archives of Emergency Medicine 2, 101-104.

17. McSwain N.E. (1981) Techniques of helmet removal from injured patients. Bulletin of the American College of Surgery 66, 19-21.

18. Apraheim C., Thompson B.M., Finger W.A. \& Darin J.C. (1984) Experimental cervical spine injury model. Evaluation of airway management and splinting techniques. Annals of Emergency Medicine 13(8), 584-587.

19. Fried L.C. (1974) Cervical spinal cord injury during skeletal traction. Journal of the American Medical Association 229(2), 181-183.

20. Committee on Trauma (1984) Advanced Trauma Life Support Instructors Manual, pp. 158. American College of Surgeons, Chicago.

21. Joyce M.S. (1988) Cervical immobilisation during ovo-tracheal intubation in trauma victims. Annals of Emergency Medicine 17(1), 88.

22. Holley J. \& Jorden R. (1989) Airway management in patients with unstable cervical spine fractures. Annals of Emergency Medicine 18(11), 1237-1239.

23. Horner C.H. \& O'Brien A.A. (1986) Motorcycle racing injuries on track and road circuits in Ireland. British Journal of Sports Medicine 20(4), 157-158.

24. Andrew T.A. (1979) A six-month review of motorcycle accidents. Injury 10(4), 317-320.

25. Zettas J.P., Zettas P. \& Thanasphan B. (1979) Injury patterns in motorcycle accidents. Journal of Trauma 19(11), 833-836.

26. Haddad J.P., Echave V., Brown R.A., Scott J.H. \& Thompson A.G. (1976) Motorcycle accidents, a review of 77 patients treated in a 3-month period. Journal of Trauma 16(7), 550-557.

27. Kupferschmid J.P., Weaver M.L., Raves J.J. \& Diamond D.L. (1989) Thoracic spine injuries in victims of motorcycle accidents. Journal of Trauma 29(5), 593-596.

28. Carr W.P., Brondt D. \& Swanson K. (1981) Injury patterns and helmet effectiveness among hospitalised motorcyclists. Minnesotta Medicine, 523-527. 
29. Larsen C.F. \& Hardt-Madsen M. (1988) Fatal motorcycle accidents in the county of Funess (Denmark). Forensic Science International 38, 93-99.

30. Krantz K.P.G. (1985) Head and neck injuries to motorcycle and moped riders - with special regard to the effect of protective helmets. Injury 16(4), 253-258.
31. Bjornstig H.L., Byland P.O., Lekander T. \& Brorsson B. (1985) Motorcycle fatalities in Sweden. Acta Chirugica Scandinavia 151, 577-581.

32. Shrosbree R.D. (1978-9) Spinal cord injuries as a result of motorcycle accidents. Paraplegia 16, 102-112. 